\title{
A farewell from your "old" editor in chief, and best wishes to the "new" editor in chief, Dr. Philippe Garrigues
}

\author{
Alvin L. Young
}

Published online: 16 April 2011

(C) Springer-Verlag 2011

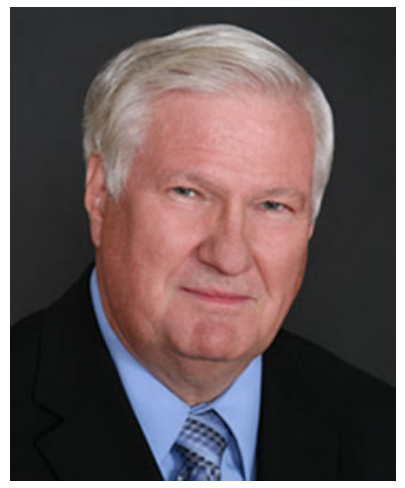

I have been a most fortunate scientist. My career has spanned more than 40 years, and I have had the honor of serving three US presidents, serving as a director of a research center, teaching as a visiting professor at a major university, and at the end of my career serving as editor in chief of Environmental Science and Pollution Research $(E S P R)$. This past September, I began to ask the question, "When is it appropriate for an editor in chief to resign?" I like to think that this is a different question than, "Is it time to replace the ESPR editor in chief?"

A. L. Young

Environmental Toxicology, The Institute

for Science and Public Policy, The University of Oklahoma, Norman, OK, USA
A. L. Young $(\bowtie)$
A.L. Young Consulting, Inc.,
1810 Tranquility Road,
Cheyenne, WY 82009, USA
e-mail: youngrisk@aol.com

In response to the first question, "When is it appropriate for an editor in chief to resign?," I developed the following criteria:

- When your status of final affiliation with a major university or research institution changes: This is important because in the absence of such affiliation, there are many in the research community that will view you as "unqualified" to judge the research manuscripts received by the journal. My affiliation with the University of Oklahoma terminated a few years ago;

- When your current or very recent past affiliation with a "cutting-edge" research program changes: This is important because you must remain current and have familiarity with how research is selected, funded, and conducted. My major research programs were funded and conducted in the United States from 1970 through 2002, and many changes and advancements have occurred worldwide, and it has become increasingly difficult to maintain currency;

- When you are invited to speak at a major university on a topic that is related to "the history of science" because you are viewed as old enough to have "been there";

- When you are invited to speak at universities and international meetings on the topics related to your role as the editor in chief, rather than on the science that you conducted;

- When all of your former students, employees, and younger colleagues speak of you as "the Old Man";

- When you stop attending international science meetings because you find too many of the sessions irrelevant to your interests, and many of the speakers are inadequately trained or prepared to present the research you are interested in hearing;

- When your fourth book was published by SpringerVerlag in April 2009, and you now realize that you really have nothing more to say about the topic; and 
- Most importantly, when it is time for you to move over and let a new generation step up to the tasks of guiding an outstanding international journal that is relevant to today's environmental challenges.

I had the great privilege of accepting the invitation to serve on the editorial board when Professor Otto Hutzinger, editor in chief, and Managing Editor Almut Heinrich published the first volume of ESPR in 1994. When Professor Hutzinger retired from the journal 7 years ago, I accepted the invitation to be the editor in chief, and I had the opportunity to guide the journal through the transition to a new publisher (Springer), a new management team, and the implementation of a system of ten responsible editors and an excellent editorial board. Now, it is my honor to pass the task of editor in chief to Dr. Philippe Garrigues.

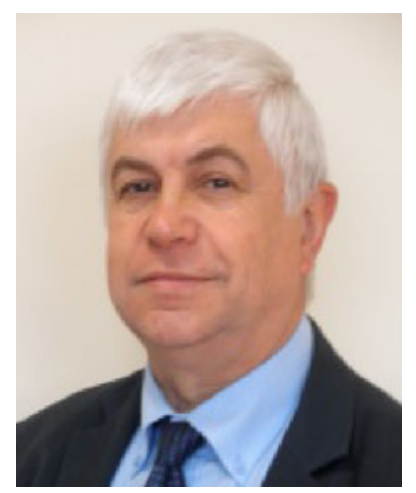

Dr. Philippe Garrigues is the research director at the French National Center for Scientific Research, Centre National de la Recherche Scientifique, and Head of the Institute of Molecular Sciences at the University of Bordeaux, France. He received a chemical engineer degree from Louis Pasteur University, Strasbourg, Alsace, France, and a $\mathrm{PhD}$ in environmental chemistry from the University of Bordeaux. His research interests are multidisciplinary covering the areas of geochemistry, environmental chemistry, and toxicology. In 1997, he was a co-founder of the Laboratory of Physico and Toxico Chemistry of Natural Systems, i.e., a laboratory of environmental chemistry and toxicology. Dr. Garrigues has authored 180 international publications and has served as an editor of several international journals including Analytical and Bioanalytical Chemistry and Polycyclic Aromatic Compounds, and for the past 2 years as an editor for ESPR. He has served on numerous scientific committees/societies and most recently as a member of the executive board of SETAC-Europe, and as the former chair of the European Division of Chemistry and the Environment. His interests in assisting young scientists and promoting the importance of science to our society will serve him well as the editor in chief of ESPR. I welcome Dr. Philippe Garrigues as the new editor in chief of ESPR.

I have many fond memories, and best of all, many old and new friends that have assisted me as editor in chief. I thank them for their tremendous support. I especially want to acknowledge the outstanding support of the Springer managerial team of Dr. Paul Roos, Monika Bechtold, Claudia Schiffers, Cristina Chua, Holger Frey, and Aaron Louie Pirante. I want to thank the excellent support and dedication of ESPR's ten editors and the excellent advice and counsel of our consulting editor, Professor Dr. Walter Giger.

With best wishes!

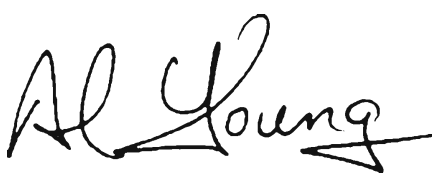

